\title{
THE INFLUENCE OF NESTBOX STYLE AND ENTRANCE HOLE SHAPE ON BOX PREFERENCES OF MOUNTAIN BLUEBIRDS AND TREE SWALLOWS
}

MYRNA PEARMAN, Ellis Bird Farm, Box 5090, Lacombe, AB T4L 1W7 and CHRISTA BECKMANN, Department of Biology, University of Regina, Regina, SK S4S OA2

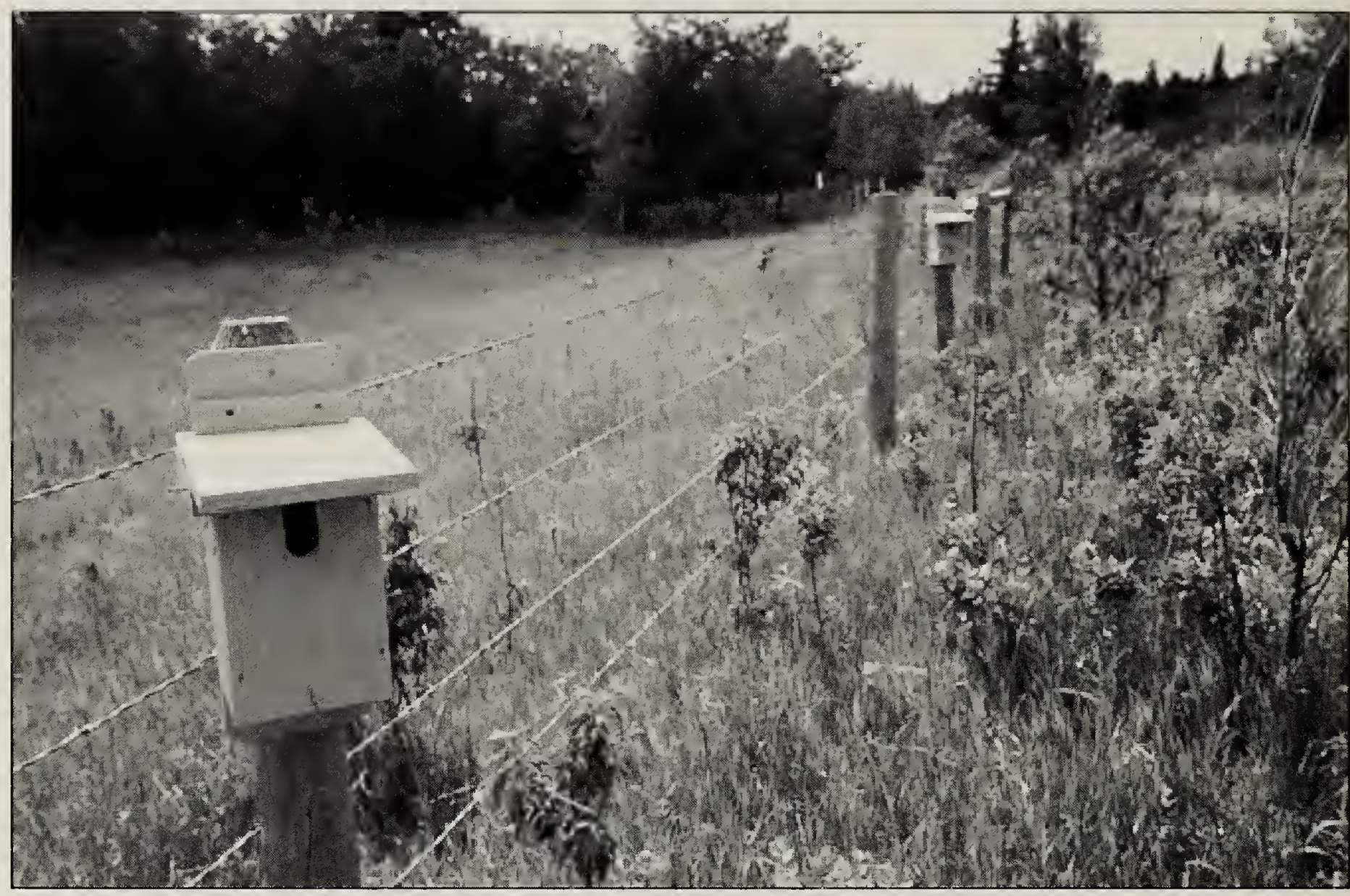

Standard box with oval hole (foreground) paired with standard box with round hole (background). Boxes in a pair were placed 8 - $10 \mathrm{~m}$ apart along the fence line.

Myrna Pearman

\section{Introduction}

There is some debate among bluebird trail operators regarding the suitability and/or superiority of different box styles. 8 One of the more vigorously debated box styles is the "Peterson" box, designed by Richard Peterson of Minnesota in the late 1970s. This box, which has a slanted front-opening panel and an oval hole, is widely used throughout Minnesota, Indiana and adjacent states. ${ }^{10}$ This box has several favorable attributes: a sloping roof that provides shade and deters predators; a slanted bottom that eliminates moisture accumulation and allows for easy nest observation and cleaning, a $35 \mathrm{~mm} \times 57 \mathrm{~mm}$ (13/8 in. $\times 21 / 4$ in.) 
oval entrance hole that allows easy access by adult birds to feed nestlings and remove fecal sacs, and a front that can be retrofitted with special sparrow traps or predator guards. However, some bluebird trail monitors have voiced concerns about increased predation potential in these boxes due to the relatively large hole and shallow nesting area, and about the risk of use by European Starlings. ${ }^{3,4,6,9}$

The issue of European Starling use is a complex one. Entrance holes larger than $40 \mathrm{~mm}$ (1 9/16 in.) will allow entry by starlings ${ }^{1}$, and although use of the Peterson box by starlings has not been found to be a significant problem, the oval entrance hole does not exclude determined starlings. . $^{3,9,10}$ Trail operators have observed, however, that both Eastern Bluebirds ${ }^{4}$ and Mountain Bluebirds ${ }^{5}$ prefer large entrance holes over smaller ones. Most trail operators use a 38-mm (1 1/2 in.) hole for Eastern and Western Bluebirds and a 40-mm (1 $9 / 16$ in.) hole for the slightly larger Mountain Bluebirds. The larger hole is also commonly used in areas where the range of the Mountain Bluebird overlaps with the other two species. ${ }^{7}$

In 1996, Berner ${ }^{2}$ set up a two-year study in upstate New York to test whether it was the Peterson box shape or the oval-shaped entrance hole that influenced box preference by Eastern Bluebirds. He set out 24 combinations of each hole/box shape (a total of 96 boxes), comparing Peterson box shapes with standard box shapes, and oval holes with round holes. The standard boxes he used had a floor size of $102 \mathrm{~mm} \times 114 \mathrm{~mm}$ (4 in. x $41 / 2$ in.) and an entrance hole of $38 \mathrm{~mm}$ (1 1/2 in.). The two-year field trial indicated that Eastern Bluebirds showed a strong preference for standard boxes with oval holes, and that Tree Swallows most frequently used Peterson-shaped boxes with round holes. In a later paper, Berner stated that it was the oval hole of the Peterson box and not its wedgeshaped design that most attracts Eastern Bluebirds. ${ }^{3}$

Since few Peterson boxes have been used within the range of the Mountain Bluebird, we conducted a field trial styled after Berner in central Alberta to compare box preference between standard and Peterson-style boxes. ${ }^{2}$ In this study, we tested whether a specific box shape alone (Peterson or standard) or entrance hole shape alone (oval or round) influenced box choice in Mountain Bluebirds. Although Mountain Bluebirds were the target species, data on box preference were also collected on Tree Swallows, which are the most common box nesters in central Alberta.

\section{Methods}

Field site and study design

Field work was conducted near Ellis Bird Farm northeast of Red Deer, Alberta for seven years between 1997 and 2003. The area is comprised of open aspen (Populus tremuloides) parkland underlain by sandy soils. The dominant land uses in the area are grazing and forage production.

We used the following nest boxes: Peterson with round holes (PR), Peterson with oval holes (PO), standard with round holes $(\mathrm{SR})$ and standard with oval holes (SO). The measurements for the Peterson box (given in the introduction above) were from Scriven ${ }^{10}$ and the standard boxes were patterned after those most commonly used throughout the range of the Mountain Bluebird: a top-opening style with $127 \mathrm{~mm} \times 127 \mathrm{~mm}$ (5 in. x 5in.) floors and a $40 \mathrm{~mm}$ (1 9/16 in.) entrance hole. 
Following Berner, ${ }^{2}$ boxes were paired so that only one attribute would be different between the boxes within each pair (i.e. hole shape or box shape). ${ }^{2}$ Five pairs of boxes of each grouping ( $1 A$, $1 \mathrm{~B}, 2 \mathrm{~A}$, and $2 \mathrm{~B}$, see below) were placed in random order on fence posts in ideal bluebird habitat along Highway 597. Boxes in a pair were $8-10 \mathrm{~m}$ apart and pairs of boxes were spaced between 150 - $450 \mathrm{~m}$ apart, depending on habitat suitability. While the sample size was small, the trial was conducted over a period of seven years.

We used two sets of pairs. To test if box shape influences box choice the pairs were: 1A, Peterson shape with round hole (PR) paired with Standard shape with round hole (SR) and $1 B$, Peterson shape with oval hole (PO) paired with Standard shape with oval hole (SO). To test if hole shape influences box choice: 2A, Standard shape with oval hole (SO) paired with Standard shape with round hole (SR). 2B, Peterson shape with oval hole (PO) paired with Peterson shape with round hole (PR).

\section{Statistical analysis}

The first species to attempt to nest in one box of the pair was recorded. The species that occupied the remaining box of the pair was not included in the data set as this bird would no longer have actively "chosen" one of the boxes but would have simply used the only remaining available box of the pair.

A box was considered "chosen" if the nesting cycle progressed to the point that the nest cup was complete. Only first nesting attempts were examined (re-nests and second broods were excluded). Uncommon bird species were excluded from statistical analysis due to low sample sizes (Black-capped Chickadee $\mathrm{N}=5$, House Sparrow $\mathrm{N}=4$ ). European Starlings also attempted to nest on five occasions; however, in each case it was determined that entry was possible because the hole was slightly larger than the required dimensions (it is difficult to make the hole precise because the elongated hole entails drilling two round holes and then joining them together using a jigsaw). In cases where starlings attempted to nest, the boxes were retrofitted with properly sized entrance hole. This retrofit successfully deterred their subsequent use by starlings.

The total number of nestboxes of each style occupied first in each box pair were summed over all years. Binomial tests were performed for each species within each pairing to determine whether a preference was exhibited for any single attribute.

\section{Results and discussion}

Neither the Peterson or standard-

Table 1. Number of nesting attempts by Mountain Bluebirds and Tree Swallows in each box pairing and test statistic from Binomial Tests.

\begin{tabular}{|c|c|c|c|c|c|}
\hline \multicolumn{2}{|r|}{ pairing } & MOBL & $\begin{array}{c}\text { test } \\
\text { statistic }\end{array}$ & TRES & $\begin{array}{c}\text { test } \\
\text { statistic }\end{array}$ \\
\hline 1A) & $\mathrm{PR}$ and $\mathrm{SR}$ & 13 and 5 & $\mathrm{p}=0.096$ & 4 and 5 & $\mathrm{p}=0.82$ \\
\hline 1B) & $\mathrm{PO}$ and $\mathrm{SO}$ & 5 and 7 & $p=0.77$ & 4 and 12 & $p=0.08$ \\
\hline 2A) & SO and SR & 9 and 3 & $p=0.15$ & 10 and 5 & $p=0.30$ \\
\hline 2B) & $\mathrm{PO}$ and $\mathrm{PR}$ & 8 and 10 & $p=0.82$ & 5 and 3 & $p=0.73$ \\
\hline
\end{tabular}




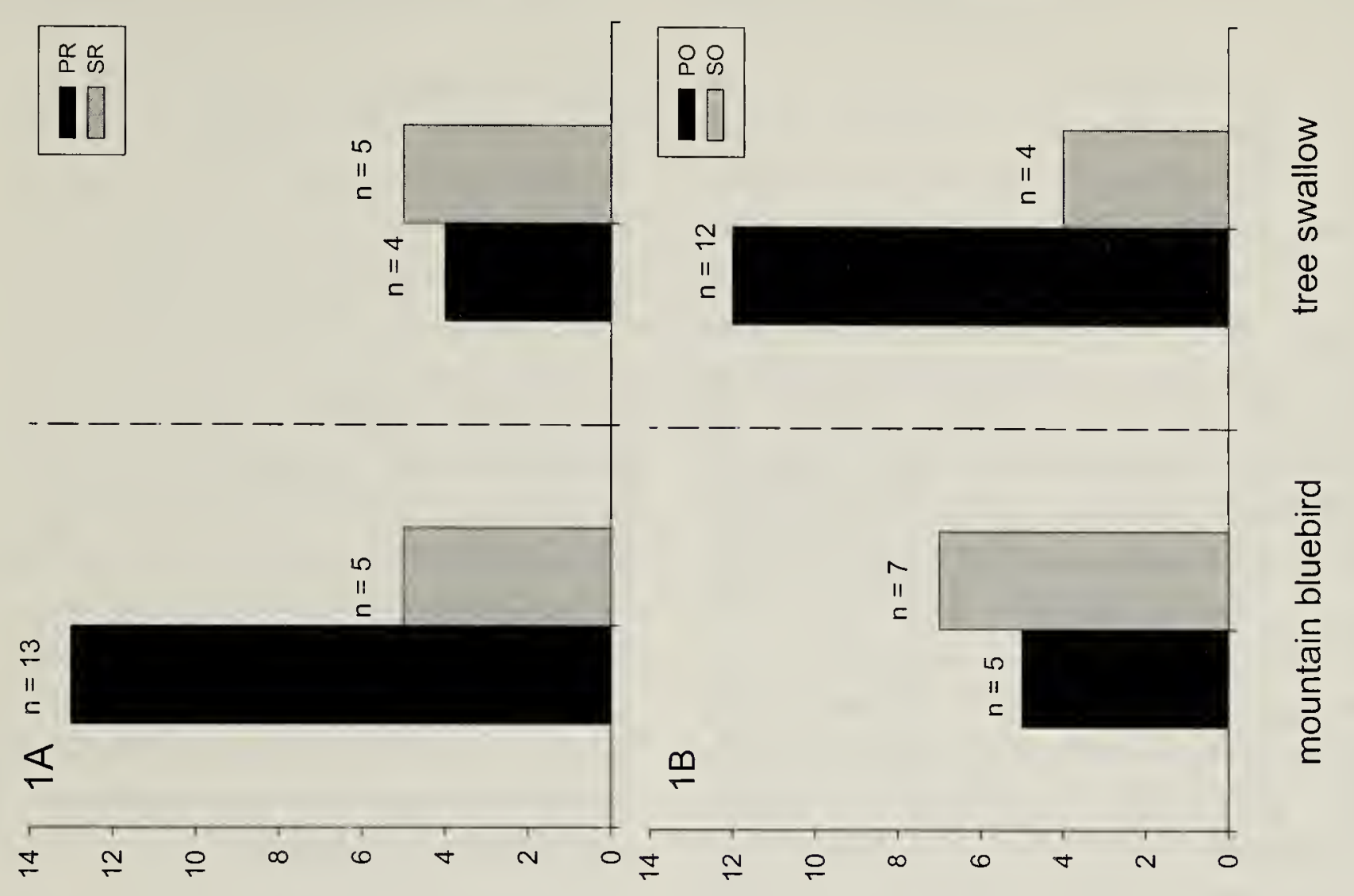

Figure 1. Number of occupied boxes summed over all years for Tree Swallows and Mountain Bluebirds; (1 A) Peterson box with round entrance (black bars) paired with standard box with round entrance (grey bars); (1B) Peterson box with oval entrance (black bars) paired with standard box with oval entrance (grey bars).

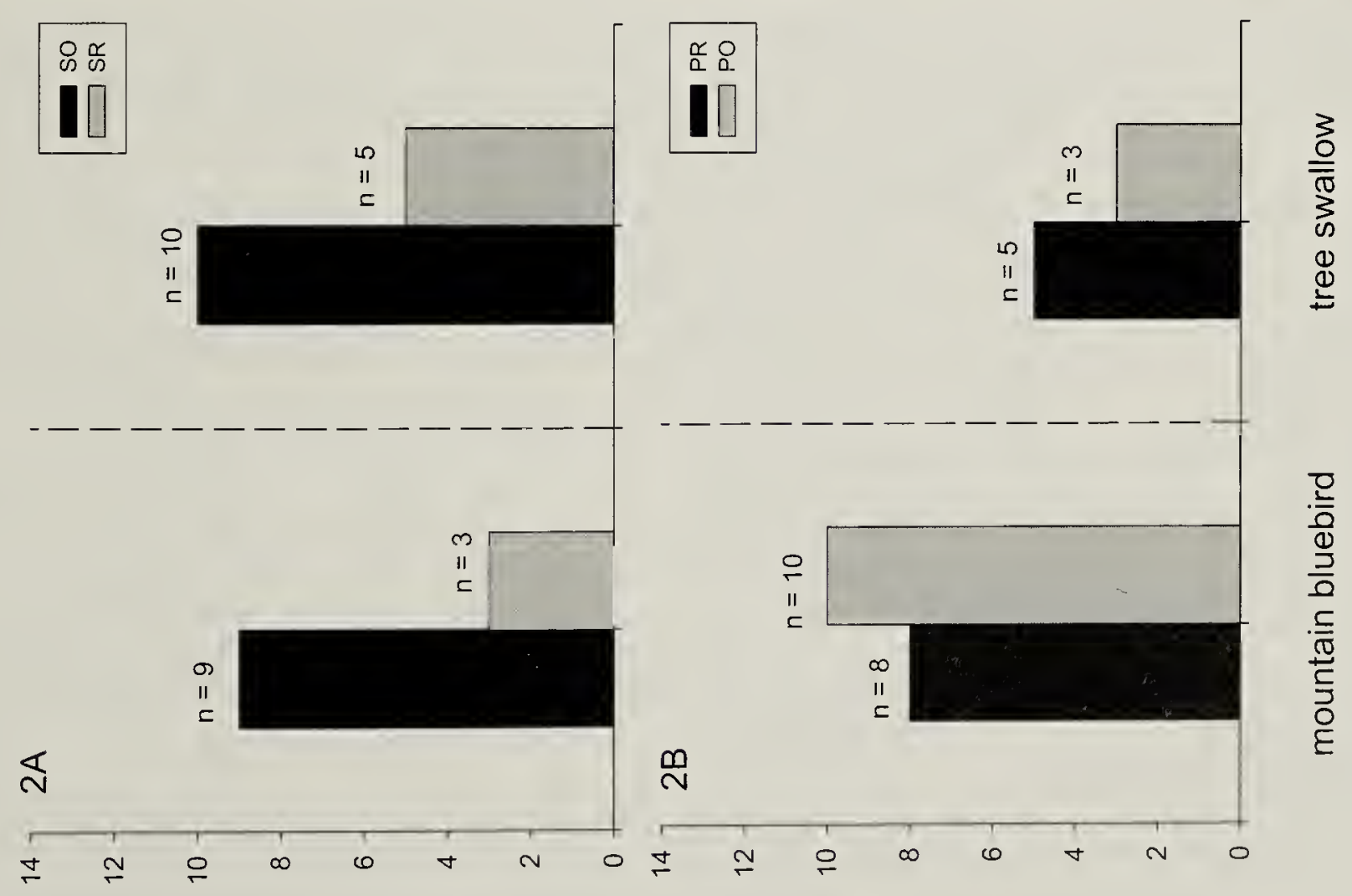

Figure 2. Number of occupied boxes summed over all years for Tree Swallows and Mountain Bluebirds; (2A) Standard box with oval entrance (black bars) paired with standard box with round entrance (grey bars); (2B) Peterson box with round entrance (black bars) paired with Peterson box with oval entrance (grey bars). 
shaped box style, nor the oval or round entrance hole influenced box choice for Mountain Bluebirds or Tree Swallows, (see Table 1, Figures 1 and 2). Sample sizes in our study were low (varying from 8 to 18), which may have contributed to our statistically nonsignificant results. If the sample size had been larger, statistically significant results may have been seen with Mountain Bluebirds for box pairing $1 \mathrm{~A}$ and Tree Swallows for box pairing 1B, as the $p$-values were approaching significance $(p=0.096$ and 0.08 respectively). This suggests that Mountain Bluebirds may prefer the Peterson box with a round entrance over the standard box with a round entrance, and Tree Swallows may prefer the standard box with an oval entrance over the Peterson box with an oval entrance. Despite using the same study design, our results are not directly comparable to Berner ${ }^{2}$ as he compared total occupancy of all boxes, not just those boxes that were first chosen within each pair.

While box design is an important factor in attracting breeding pairs of bluebirds, the overall goal of a bluebird trail is to maximize reproductive success. It is therefore important to examine the nesting success, not just box choice, in boxes of various designs. We intend to analyze the nesting data of all the boxes used in this study to determine whether or not reproductive success varied with box style.

\section{Acknowledgements}

This study was conducted as part of the Ellis Bird Farm Ltd.'s bluebird conservation program. It was overseen by Ellis Bird Farm Research Committee members, Dr. Bob Lane and Bill Baile.
Funding assistance for supplies required to build the boxes was provided by the Red Deer and District Community Foundation (RDDCF) though their Conservation of Bluebirds, Swallows and other Native Cavity Nesting Birds (Field of Interest) Fund. Funding for the analysis of the data was provided by the Red Deer River Naturalists (RDRN). Thanks to Kevin Berner for his assistance with setting up the study and reviewing the manuscript, to the Ellis Bird Farm Board of Directors for their ongoing support, and to both RDDCF and the RDRN for financial assistance. We would also like to thank Bernie Daniel and Meghan Ford for assisting with some of the preliminary analyses.

1. AYLESWORTH, A. 1984. Large box openings can be curse or blessing. Sialia 6(4): 123-124

2. BERNER, K. 1998. Dissecting the Peterson nest box. Sialia 20(1): 11-13

3. BERNER, K. 1999. Starlings and oval-holed nest boxes. Bluebird 21(1): 6-7

4. BERNER, K. 2002. Non-traditional nest box holes: Disaster or opportunity for bluebirders? Sialia 24(1): 7-9

5. HAGERMAN, D. 1988. Nesting box entrance hole size preferred by Mountain Bluebirds. Sialia 10(3): 83-86

6. LEHMANN, D. 1997. Control tests to determine if European Starlings can pass through various hole sizes. Sialia 19(4): 125-131

7. PEARMAN, M. 1999. The great entrance hole debate. Sialia 21(2): 8-9

8. PEARMAN, M. 2002. Mountain Bluebird Trail Monitoring Guide. Red Deer River Naturalists, Red Deer.

9. SCRIVEN. D 1995. Do Peterson boxes "readily admit" starlings? Sialia 17(3): 98-99

10. SCRIVEN, D. 1999. Bluebird Trails: A Guide to Success (3rd Edition). Bluebird Recovery Program, Minneapolis. 